ScIDice

\section{International Journal of Dentistry and Oral Science (IJDOS) \\ ISSN: 2377-8075}

\title{
Fear Of Dental Extraction
}

Research Article

Dhanraj Ganapathy ${ }^{1 *}$, Sivesh Sangar ${ }^{2}$, Hemavathy Muralidoss ${ }^{3}$

${ }^{1}$ Professor and Head, Department of Prosthodontics, Saveetha Dental College, Saveetha Institute of Medical and Technical Sciences, Chennai-77, India 162, Poonamallee High Road Chennai 600077 Tamil Nadu, India.

${ }^{2}$ Undergraduate Student Saveetha Dental College, Saveetha Institute of Medical and Technical Sciences, Chennai-77, India.

${ }^{3}$ Reader, Department of Oral and Maxillofacial Surgery Saveetha Dental College, Saveetha Institute of Medical and Technical Sciences, Chennai-77, India.

\section{Abstract}

This study is done to evaluate and elicit the fear of dental extraction among the adult population visiting Saveetha Dental College and Hospital. A cross sectional questionnaire survey was carried out to assess the fear of dental extraction among people a simple random sampling was done. Convenient sample size of 100 patients was decided. Data collected through a questionnaire and analysis done based on the answers. The result of this study might demonstrate the fear of dental extraction among the public and gives us a better understanding to create a platform to reduce the fear of dental extraction and management of the same. The conclusion of the study indicates that fear of dental extractions is due to the anxiety of the patient caused by environmental factors around the dental setting. Fear of dental extractions are mostly fuelled by stories from friends and family. With these results in hand, we can plan for a proper module and teaching manual to educate the patients who are to undergo extraction as that would be able to reduce the amount of fear and anxiety present in the patients. We could also educate the patients on the importance of removing a grossly decayed tooth as well as the effect and future deterministic causes of not removing the tooth.

Keywords: Dental Extractions; Fear; Patients; Anxiety; Pain.

\section{Introduction}

Fear and anxiety has been recognized as an important problem among the patients who come for dental extraction [1]. The concept of dental fear refers to patients feeling fear some and worried about future dental care and their appearance post treatment [2]. The fear ranges from mild to extreme fear, extreme fear is associated with poor oral health as a result of less frequent or irregular dental visits as well as delay and cancellation of dental appointments [3]. Fear can cause the patient to become irrational and resist treatments [4].

It has been argued that these characteristics feed in to a 'vicious cycle', where by the level of dental anxiety is either reinforced or increased as a result of greater disease prevalence and severity as- sociated with delayed dental visiting [5]. It is because of the growing understanding and appreciation of the significance of these associations that the study of dental fear has assumed increasing importance in dental research [6].

References to the concept of a vicious cycle of fear are replete within the psychological literature [7-11], however no systematic effort has yet been made to apply this idea in an analytical fashion to dental fear [12]. For the most part, the idea of a 'vicious cycle' has been used post hoc to explain the relationship between dental fear and dental visiting behaviours without any substantive effort to explore the chain of relationships presupposed by the concept [13].

The aim of this study was, therefore, not only to explore, with in a contemporary Oceanicpopulation, the relationship between

\section{*Corresponding Author:}

Dhanraj Ganapathy,

Professor and Head, Department of Prosthodontics, Saveetha Dental College, Saveetha Institute of Medical and Technical Sciences, Chennai-77, India 162, Poonamallee High Road Chennai 600077 Tamil Nadu, India.

Email Id: dhanrajmganapathy@yahoo.co.in

Received: April 12, 2021

Accepted: May 08, 2021

Published: May 17, 2021

Citation: Dhanraj Ganapathy, Sivesh Sangar, Hemavathy Muralidoss. Fear Of Dental Extraction. Int J Dentistry Oral Sci. 2021;08(05):2470-2473. doi: http://dx.doi.org/10.19070/2377-8075-21000485

Copyright: Dhanraj Ganapathy ${ }^{\circ} 221$. This is an open-access article distributed under the terms of the Creative Commons Attribution License, which permits unrestricted use, distribution and reproduction in any medium, provided the original author and source are credited. 
dental fear and dental visiting patterns, prevalence of dental problems and symptom-driven treatment but to examine the hypothesized sequence of the 'vicious cycle' of fear, where by dental fear, delayed dental visits, increased dental problems and symptom-driven treatment form a linked chain feeding back into the fear experience.

\section{Materials and Methods}

A cross sectional questionnaire survey was carried out to assess the fear of dental extraction among people. A simple random sampling was done. Convenient sample size of 100 people was decided. Data was collected by questionnaire. A special designed questionnaire consisting of 15 close ended questions was used to assess fear of dental extraction among people. The identity of the people was maintained confidential. The filled questionnaire was immediately collected after answering and analysed.

\section{Sample Size:}

100 participants were included in study.

Table 1. shows the response of participants towards amount of fear regarding dental extraction.

\begin{tabular}{|c|c|}
\hline \multicolumn{2}{|c|}{ How fearful are you towards dental extraction? } \\
\hline Anxious & $28 \%$ \\
\hline Fear & $31 \%$ \\
\hline Very Anxiety & $22 \%$ \\
\hline Frightened & $19 \%$ \\
\hline
\end{tabular}

Figure 1. Shows the response of participants regarding potential barrier for avoiding routine visit to dentist.

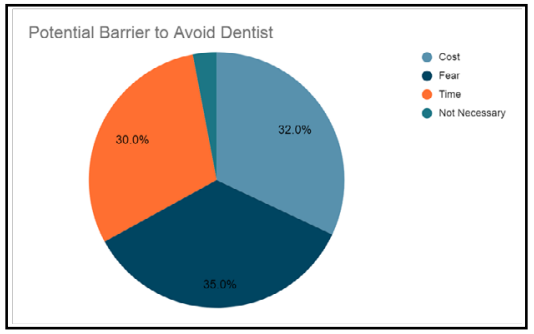

Figure 2. Shows the response of participants towards feeling of patient when teeth going to be extracted.

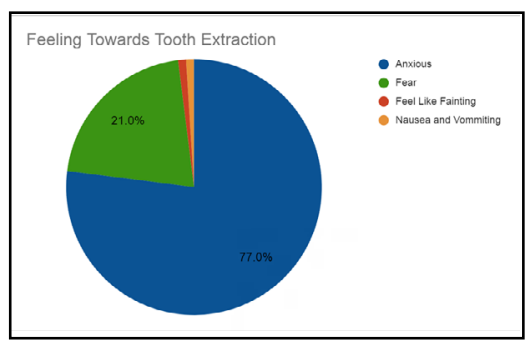

Figure 3. Shows the response for element of people mostly scared about extraction.

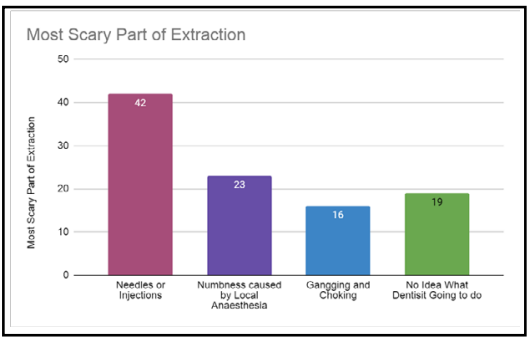

Figure 4. Shows the reaction of participants towards statement of placing a forceps ever made them cry and panic.

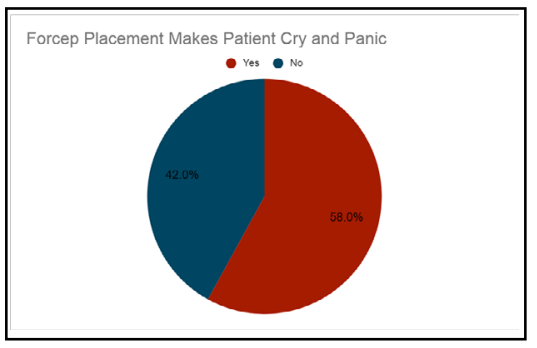


Table 2. Shows the remaining questions and response of participants regarding fear towards dental extraction.

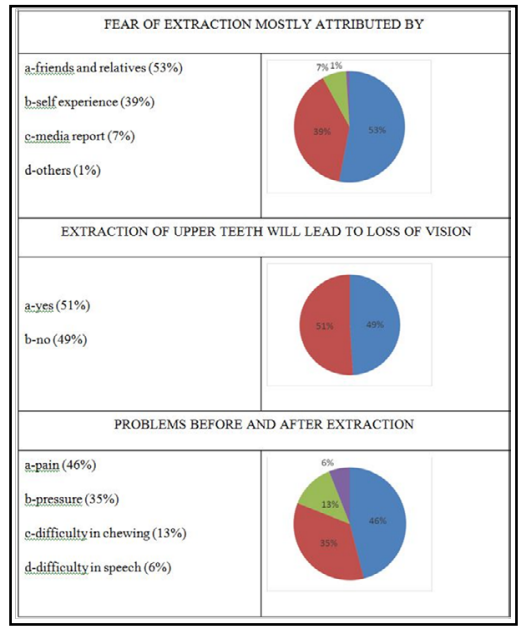

\section{Criterias:}

Inclusion criteria included generally healthy males and females aged 18 years and older with a normal salivary flow rate and who were willing to undergo the study. Participants informed priorly about the need and reason for the study. Exclusion criteria were as follows: patient with a history of: diabetic mellitus, hypertension, stroke, cardiac conditions, oral cancer or radiation therapy to head and neck region, current or recovering alcoholism, known allergies to any of the test product ingredients, any medical conditions that may interfere with study and participants who are pregnant and lactating

\section{Data Analysis:}

The data entry was done in Microsoft excel. The data was analyzed using descriptive statistics done.

\section{Result}

\section{Discussion}

Fear is defined by the Oxford Dictionary as "An unpleasant emotion caused by the threat of a danger, pain or harm." Dental fear was found to be related to less frequent dental visiting, whether measured by past behaviour or future intentions, more prevalent dental problems, whether assessed by the number of teeth missing, perceived need, social impact or self-rated oral health, and symptom-driven treatment as measured by a person's usual reason for visiting. These findings support those of a number of other studies both within Australia and elsewhere. In Australia, for example, Thomson et al. found higher dental fear for people who last visited the dentist more than 2 years ago, who usually visited for a problem, and who experienced social impacts resulting from their oral health state [14].

Subjects tend to overestimate their fear of dental pain when they have not actually experienced the particular pain itself. This result was reversed with in the sample of highly anxious dental patients in whom personal experience with an item led to higher fear of dental pain for that item. For the sample of periodontal patients, higher levels of fear of dental pain were associated with more pain felt during probing [15]. For the sample of highly anxious dental patients, stronger reductions in dental anxiety were associated with lower levels of fear of dental pain.

People who were very afraid of going to the dentist had more missing teeth than did people with less or no fear. The number of missing teeth has previously been found to be a more sensitive marker of dental fear than the traditional measure of the number of decayed, missing or filled teeth (DMFT). For instance, Schuller et al. found that while there was no statistically significant difference between the DMFT scores of individuals with high or low dental fear, the number of missing teeth was almost $50 \%$ higher among high dental fear than among low dental fear people [16]. This was interpreted as a preference for high fear people to have their teeth extracted instead of restored. However, it is also possible that the increased number of teeth extracted might be as a result of differences in the progression of carious lesions between people with high and low fear when they finally seek treatment. This fits well with the belief of Bouma et al. that if the vicious cycle of fear, treatment need and negative treatment experience is not broken the eventual consequence is full mouth extraction [17].

In many countries, use of dental services may be strongly related to access to oral health care. In Australia, at least theoretically, dental services are universally available. Publicly funded dental care, however, is rationed and available to those earning less than a specified income, who are on an invalid or old-age pension or who are war veterans. About one-quarter of Australians are eligible to receive public-funded dental care [18]. Income strongly affects access to services in relation to both private dental services and public dental care which may be characterised by lengthy waiting lists. It is therefore not surprising that this study found household income to be significantly associated with the vicious cycle phenomenon. People on lower income invariably have both increased oral disease experience and more barriers to accessing dental care. Nonetheless, even after controlling for household income, dental fear was significantly associated with having characteristics associated with a vicious cycle.

Apart from the roles that delaying dental visiting and subsequent invasive treatments are proposed to have on heightening or maintaining dental fear, a number of researchers have stressed the importance of escalating psychological factors in contributing to a vicious cycle of dental fear. For instance, catastrophizing 
ideations have been found among people with dental fear [19] and this is believed to impact on both the physical and emotional distress experienced during a dental examination [16] and on the perceived pain of treatment $[20,21]$. It has also been argued that a strong sense of embarrassment, especially following many years of avoidance, related to feelings of self-punishment, shame and negative self-image may be an important aspect of a vicious cycle of dental anxiety $[22,23]$. While this paper did not look at these various psychological factors, it is quite likely that these and other cognitive and emotional components help to facilitate the progression in the vicious cycle involving fear and dental decay.

This study found almost one in three people with high dental fear fit the profile hypothesised by a vicious cycle of dental fear, having delayed dental visiting, poorer oral health and symptomatic dental visiting patterns. The idea of a vicious cycle of dental fear can be used to describe the specific clustering of detrimental behavioural and oral health outcomes in some people, which may serve to perpetuate or even exacerbate the anxiety and fear associated with dental visiting [24]. In future research, there may be value in attempting to differentiate between people with high dental fear and those who might have potentially diagnosable dental phobia as well as look at differences in coping strategies of both high- and low-fear people and of high-fear people who fit a vicious cycle profile and high-fear people who manage to maintain regular dental visiting patterns.

\section{Conclusion}

The study has shown that the fear of visiting the dentist is caused by the patient's anxiety and fear of the dental environment. The potential barrier for avoiding routine visits to the dentist is due to three main factors which are cost, fear and time constraints. When the patient is suggested to undergo an extraction, most patients say they are anxious and do not know what to expect and that the extraction of the tooth might change their appearance. Most patients are most scared due to needles and injections. More than half of the patients surveyed said that the placement of the forceps has made them cry and panic. Fear of dental extractions are mostly fuelled by stories from friends and family. More than half of the surveyed patients believe a superstition that extraction of upper teeth would lead to loss of vision. Most patients complain of pain that exists both before and after extractions. With these results in hand, we can plan for a proper module and teaching manual to educate the patients who are to undergo extraction as that would be able to reduce the amount of fear and anxiety present in the patients. We could also educate the patients on the importance of removing a grossly decayed tooth as well as the effect and future deterministic causes of not removing the tooth. We also need to build a better personal relationship with the patient so the patient would have trust in the dentist which would ultimately reduce the amount of fear felt by the patient.

\section{References}

[1]. Wahab AS, Aboulouz AS. Comparison between Forceps, Single Blade Forceps and Manual Extraction of Fetal Head in Elective Caesarean Section: A Randomized Control Trial—Forceps Delivery in Cesarean Section. Open Journal of Obstetrics and Gynecology. 2018 Jan 3;8(1):31-8.

[2]. Milgrom P, Newton JT, Boyle C, Heaton LJ, Donaldson N. The effects of dental anxiety and irregular attendance on referral for dental treatment under sedation within the National Health Service in London. Community
Dent Oral Epidemiol. 2010 Oct;38(5):453-9. Pubmed PMID: 20545723.

[3]. Kumar S, Paul A, Chacko R, Deepika S. Time required for haemostasis under pressure from dental extraction socket. Indian J Dent Res. 2019 NovDec;30(6):894-898. Pubmed PMID: 31939367.

[4]. Coulthard P, Bridgman CM, Gough L, Longman L, Pretty IA, Jenner T. Estimating the need for dental sedation. 1. The Indicator of Sedation Need (IOSN) - a novel assessment tool. Br Dent J. 2011 Sep 9;211(5):E10. Pubmed PMID: 21904334.

[5]. Newton JT, Buck DJ. Anxiety and pain measures in dentistry: a guide to their quality and application. J Am Dent Assoc. 2000 Oct;131(10):1449-57. Pubmed PMID: 11042984.

[6]. Buchanan H. Acquisition and measurement of dental anxiety: a summary paper. Soc Sci Dent. 2012;2:10-6.

[7]. Eapen BV, Baig MF, Avinash S. An Assessment of the Incidence of Prolonged Postoperative Bleeding After Dental Extraction Among Patients on Uninterrupted Low Dose Aspirin Therapy and to Evaluate the Need to Stop Such Medication Prior to Dental Extractions. J Maxillofac Oral Surg. 2017 Mar;16(1):48-52. Pubmed PMID: 28286384.

[8]. Marimuthu MA, Wahab PA, Balakrishnan A, SHANMUGAM S, NARAYANAN V, MUTHUSEKHAR M. EXPRESSION ANALYSIS OF CANONICAL WNT PATHWAY GENES IN ORAL SQUAMOUS CELL CARCINOMA AND THEIR POSSIBLE ROLE AS BIOMARKERS. Oral surgery, oral medicine, oral pathology and oral radiology. 2017 Sep 1;124(3):e197.

[9]. Jain A. Accidental displacement of Mandibular first molar root into buccal space: A unique case. J Stomatol Oral Maxillofac Surg. 2018 Nov;119(5):429431. Pubmed PMID: 29679739.

[10]. Sweta VR, Abhinav RP, Ramesh A. Role of Virtual Reality in Pain Perception of Patients Following the Administration of Local Anesthesia. Ann Maxillofac Surg. 2019 Jan-Jun;9(1):110-113. Pubmed PMID: 31293937.

[11]. Ramadorai A, Tay ABG, Vasanthakumar G, Lye WK. Nerve Injury After Surgical Excision of Mandibular Third Molars Under Local Anesthesia: An Audit. J Maxillofac Oral Surg. 2019 Jun;18(2):307-313. Pubmed PMID: 30996556.

[12]. Humphris GM, Morrison T, Lindsay SJ. The Modified Dental Anxiety Scale: validation and United Kingdom norms. Community Dent Health. 1995 Sep;12(3):143-50. Pubmed PMID: 7584581.

[13]. King K, Humphris G. Evidence to confirm the cut-off for screening dental phobia using the Modified Dental Anxiety Scale. Soc Sci Dent. 2010;1(1):21-8.

[14]. Chrysanthakopoulos NA. Reasons for extraction of permanent teeth in Greece: a five-year follow-up study. Int Dent J. 2011 Feb;61(1):19-24. Pubmed PMID: 21382029.

[15]. Carranza FA, Camargo PM. The periodontal pocket. Carranza’s clinical periodontology. 2012;9:349.

[16]. Petersen PE, Yamamoto T. Improving the oral health of older people: the approach of the WHO Global Oral Health Programme. Community Dent Oral Epidemiol. 2005 Apr;33(2):81-92. Pubmed PMID: 15725170.

[17]. Phipps KR, Stevens VJ. Relative contribution of caries and periodontal disease in adult tooth loss for an HMO dental population. J Public Health Dent. 1995 Fall;55(4):250-2. Pubmed PMID: 8551465.

[18]. Murray H, Locker D, Kay EJ. Patterns of and reasons for tooth extractions in general dental practice in Ontario, Canada. Community Dent Oral Epidemiol. 1996 Jun;24(3):196-200. Pubmed PMID: 8871019.

[19]. Armfield JM, Spencer AJ, Stewart JF. Dental fear in Australia: who's afraid of the dentist? Aust Dent J. 2006 Mar;51(1):78-85. Pubmed PMID: 16669482.

[20]. Shigli K, Hebbal M, Angadi GS. Relative contribution of caries and periodontal disease in adult tooth loss among patients reporting to the Institute of Dental Sciences, Belgaum, India. Gerodontology. 2009 Sep;26(3):214-8. Pubmed PMID: 19018874.

[21]. Caldas AF Jr. Reasons for tooth extraction in a Brazilian population. Int Dent J. 2000 Oct;50(5):267-73. Pubmed PMID: 15988885.

[22]. Akhter R, Hassan NM, Aida J, Zaman KU, Morita M. Risk indicators for tooth loss due to caries and periodontal disease in recipients of free dental treatment in an adult population in Bangladesh. Oral Health Prev Dent. 2008;6(3):199-207. Pubmed PMID: 19119574.

[23]. Byahatti SM, Ingafou MS. Reasons for extraction in a group of Libyan patients. Int Dent J. 2011 Aug;61(4):199-203. Pubmed PMID: 21851351.

[24]. Ong G, Yeo JF, Bhole S. A survey of reasons for extraction of permanent teeth in Singapore. Community Dent Oral Epidemiol. 1996 Apr;24(2):1247. Pubmed PMID: 8654033. 